\title{
True Stability of Lubricants Determined Using the Ball-on-Disk Test
}

\author{
Angela Maria Tortora and Deepak Halenahally Veeregowda \\ Application Development Laboratory, Ducom Instruments Europe B.V., 9713 GX Groningen, Netherlands
}

Correspondence should be addressed to Deepak Halenahally Veeregowda; deepak.v@ducom.com

Received 17 October 2015; Accepted 29 December 2015

Academic Editor: Huseyin Çimenoğlu

Copyright (C) 2016 A. M. Tortora and D. Halenahally Veeregowda. This is an open access article distributed under the Creative Commons Attribution License, which permits unrestricted use, distribution, and reproduction in any medium, provided the original work is properly cited.

\begin{abstract}
True stability of lubricants can be determined when there is minimum change in the contact area and also the intervention of wear debris in the contact zone. Here, we have used the ball-on-disk instrument with the migrating point contact, that is, relative motion between the ball and disk condition to fix the contact area and minimize the wear debris at the contact zone. The jump in the friction coefficient indicates the film failure, which appeared earlier for the motor oil 5W30 compared to 5W40. Such profile was not recorded in absence of relative motion. Therefore, 5W40 was considered to have a better lubricant stability than 5W30. Applying the same test condition to the natural lubricants shows that glycerol has better lubricant stability than glycerol-water mixture. Superior true lubricant stability by glycerol and 5W40 can be related to its high viscosity. However, they were less wear resistant compared to low viscosity lubricants like 5W30 and glycerol-water. We suspect the role of microscopic wear debris at the contact zone for this behavior although it should have been avoided in the migrating point contact condition. Overall, ball-on-disk instrument with a migrating point contact condition is an effective technique to determine the stability of lubricants.
\end{abstract}

\section{Introduction}

An effective lubrication can be achieved with a lubricating film that is stable during the hydrodynamic, mixed, and boundary conditions. Four ball [1], ball-on-disk [2], and block-on-ring instruments [3] are some of the well-established industrial standard techniques used in tribological characterization of the lubricants. However, its application in studying the stability of the lubricants has been limited due to the fixed motion between the contacts [4]. In these techniques, true contact area during the test is increasing due to wear and it reduces the true contact pressure. Such a drop in the true contact pressure can facilitate higher load carrying capability of a lubricant. Moreover, the wear debris accumulated at the contact zone can increase or decrease the loading carrying capability of a lubricant [5]. Overall, the true stability of a lubricant is misrepresented due to the decrease in contact pressure and accumulation of wear debris. Therefore, it is important to fix the contact area, avoid intervention of wear debris at the contact zone, and determine the true stability of the lubricants.

The aim of this research is to use a modified ball-on-disk technique to investigate the friction, wear, and true stability of the lubricating films. Two types of contact conditions in the ball-on-disk test, (i) migrating point, that is, relative motion between the ball and disk, and (ii) fixed point and fixed point-variable speed contact, that is, no relative motion between the ball and disk, are used in this study. Synthetic lubricants like the motor oil 5W40 and 5W30 and natural lubricants like the glycerol and glycerol-water mixture were tested using the ball-on-disk. The friction coefficient of the lubricants was measured using the ball-on-disk test, the disk wear was qualitatively and quantitatively determined using a noncontact profilometer. The friction coefficient profile from the ball-on-disk test was used to evaluate the stability of the lubricants. 


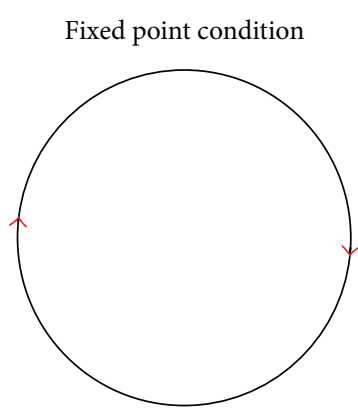

(a)

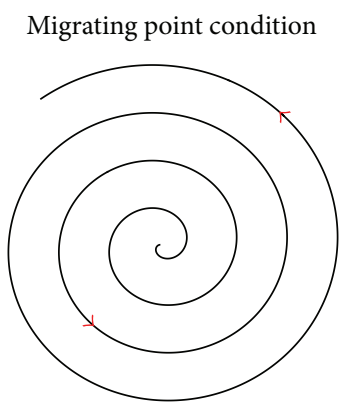

(b)

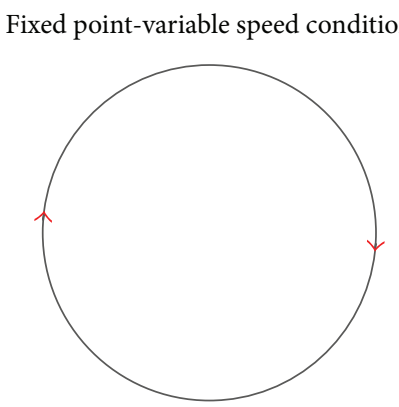

(c)

FIGURE 1: Different contact conditions in the ball-on-disk test. (a) fixed point condition and circular geometry, (b) migrating point condition and spiral geometry, and (c) fixed point-variable speed condition and circular geometry.

\section{Materials and Methods}

2.1. Lubricants. Synthetic lubricants were multigrade motor oils of viscosity grade 5W30 and 5W40 (from the same manufacturer) and the natural lubricants were glycerol $(99.9 \%$ pure, Sigma Aldrich, Germany) and glycerol-water mixture (glycerol diluted in water to have a final concentration of $50 \%$ $\mathrm{w} / \mathrm{w})$.

2.2. Friction Coefficient of Lubricants. Friction coefficient (COF) of the lubricants was determined using the ball-ondisk instrument (TR 20, Ducom Instruments Pvt. Ltd., India). Silicon Nitride $\left(\mathrm{Si}_{3} \mathrm{~N}_{4}\right)$ ceramic balls of $6 \mathrm{~mm}$ in diameter and Inconel 617 (IN617) disks of $60 \mathrm{~mm}$ in diameter were used in this study. Ball was pressed on the rotating disk at a normal force of $6.5 \mathrm{~N}$. Ball position could be either fixed or reciprocating. The reciprocating motion was achieved through a stepper motor, pulley, and a linear guide arrangement. Servo motor was used to vary the speed of the disk between $1000 \mathrm{rpm}$ and $1 \mathrm{rpm}$. Disk was enclosed within a chamber that can hold a lubricant of $2 \mathrm{~mL}$ in volume. Friction force at the point contact between the ball and disk was measured using a button type load cell. The friction coefficient of a lubricant was determined by dividing the friction force with the respective normal force.

Friction coefficient of the lubricants was determined at different contact conditions. All these contact conditions were software controlled using the labview based Winducom 2010 software (Ducom Instruments Pvt. Ltd., India). The duration of the test was fixed at $60 \mathrm{~s}$ and the total distance travelled was fixed at $86 \mathrm{~m}$.

2.3. Fixed Point Contact Condition. The ball position was fixed over the disk at a wear track diameter of $28 \mathrm{~mm}$ and the disk was rotating at a fixed speed of $1000 \mathrm{rpm}$. The geometric shape of this wear track was circular as illustrated in Figure 1(a). In this condition there were multiple passes over a single wear track.

2.4. Migrating Point Contact Condition. The ball was linearly moved away from the center of the disk at a sliding speed of $0.5 \mathrm{~mm} / \mathrm{s}$ while the disk was rotating at a speed of $1000 \mathrm{rpm}$.
The geometric shape of this wear track was spiral as illustrated in Figure 1(b). In this condition there were no multiple passes over a single wear track.

2.5. Fixed Point-Variable Speed Contact Condition. The ball position was fixed over a disk at a wear track diameter of $28 \mathrm{~mm}$ and the disk was rotating at a variable speed. The disk speed decreased exponentially from $1000 \mathrm{rpm}$ to $70 \mathrm{rpm}$ within the testing duration of $60 \mathrm{~s}$. The geometric shape of this wear track was circular as illustrated in Figure 1(c). In this condition there were multiple passes over a single wear track and it was at different sliding speeds.

2.6. Surface Topography and Wear Area. Three-dimensional images of the wear track on the disk surface were captured using a noncontact profilometer (Proscan 2000, Scantron Industrials Ltd., UK). A white light chromatic sensor with a maximum measuring range of $0.3 \mathrm{~mm}$ was used in the profilometer. The scan rate and the scan area were fixed at 300 points per second and $2 \mathrm{~mm} \times 2 \mathrm{~mm}$, respectively. The disks after the friction test were cleaned with $70 \%$ ethanol and later the wear track was imaged. The depth and width of the wear track on the disk were calculated by using the Proscan software (Scantron Industrials Ltd., UK). The geometry of the wear track was parabolic and its area was calculated using

$$
\text { Wear area }=\frac{2}{3}(\text { depth } \times \text { width }) .
$$

\section{Results}

3.1. Friction Coefficient of Synthetic Lubricants. In the fixed point contact condition (Figure 2(a)) the run-in friction coefficient for motor oil 5W30 and 5W40 was 0.381 and 0.260 . After the run-in phase, the friction coefficient of the motor oil 5W40 stabilized earlier than the motor oil 5W30. The stable friction coefficient of 5W40 was 0.022 and it was two times lower than motor oil 5W30.

In the migrating point contact condition (Figure 2(b)) there was no run-in phase for the motor oils. For 5W30, at $23 \mathrm{rd}$ s of testing the friction coefficient suddenly jumped from 0.073 to 0.383 . Similar jump in the friction was recorded for 

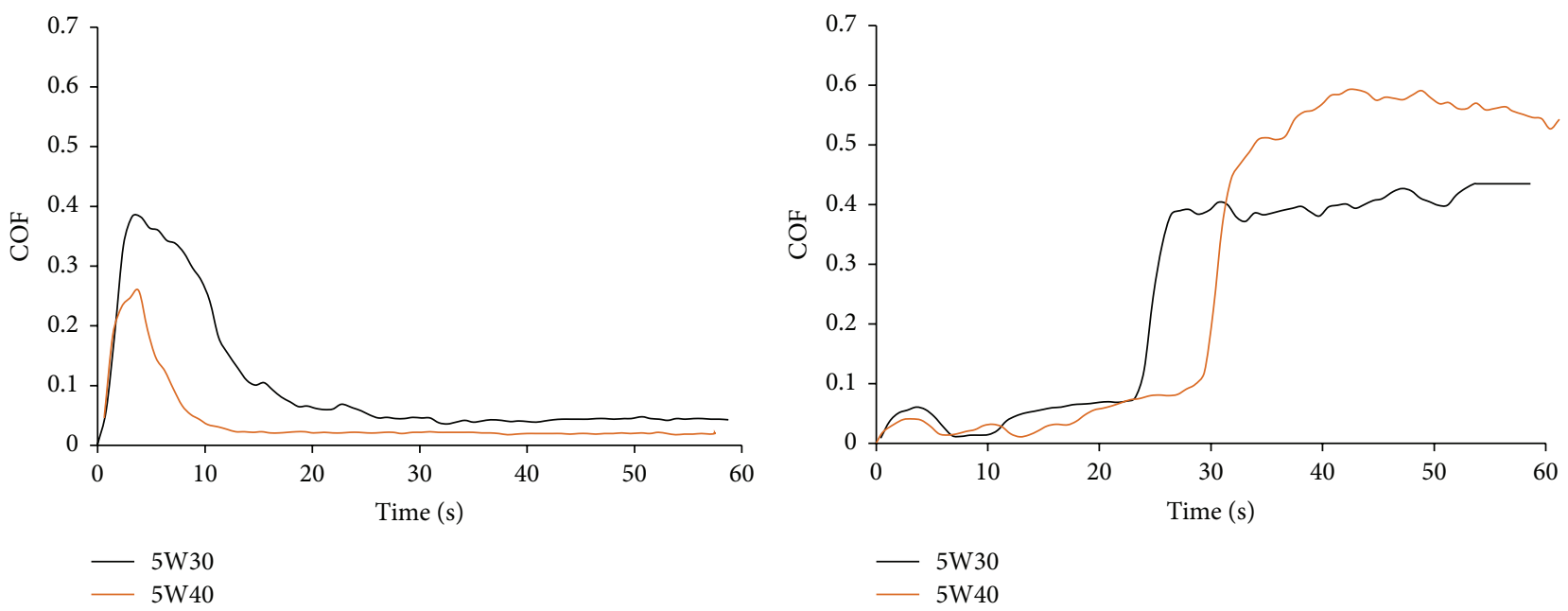

(a)

(b)

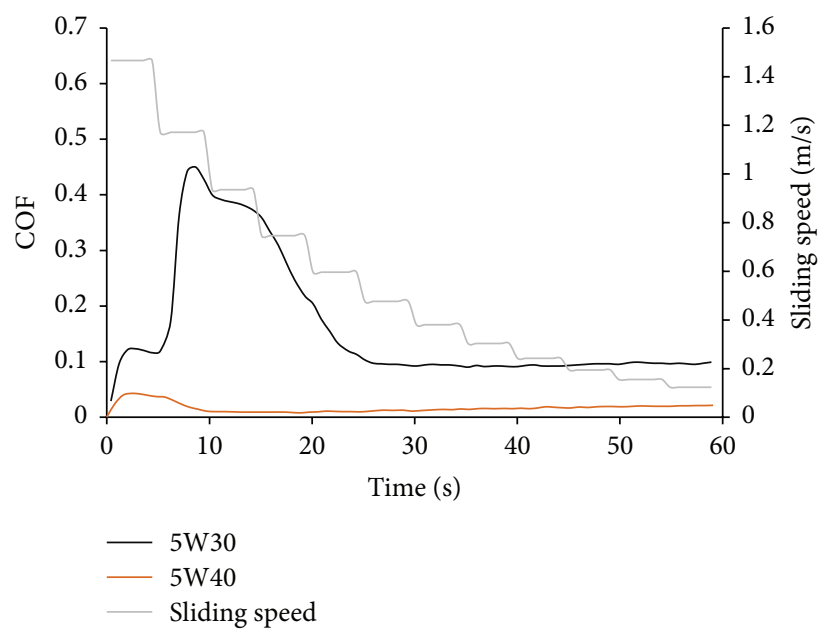

(c)

FIGURE 2: Friction coefficient (COF) of motor oil 5W30 and 5W40. (a) fixed point condition and circular geometry, (b) migrating point condition and spiral geometry, and (c) fixed point- variable speed condition and circular geometry.

$5 \mathrm{~W} 40$ at 30 th $\mathrm{s}$ and the friction after failure was higher than $5 \mathrm{~W} 30$.

In the fixed point-variable speed contact condition (Figure 2(c)) the friction coefficient for the motor oil 5W30 decreased from 0.442 to 0.097 when the sliding speed decreased from $1.30 \mathrm{~m} / \mathrm{s}$ to $0.47 \mathrm{~m} / \mathrm{s}$. The friction coefficient for the motor oil 5W40 was always lower than 5 W30. Its friction coefficient decreased from 0.098 to 0.025 when the sliding speed decreased from $1.30 \mathrm{~m} / \mathrm{s}$ to $1.17 \mathrm{~m} / \mathrm{s}$.

3.2. Friction Coefficient of Natural Lubricants. In the fixed point contact condition (Figure 3(a)) the run-in friction coefficient for glycerol-water mixture was 0.383 . And, there was no run-in phase when the glycerol was used as a lubricant. The stable friction coefficient for glycerol-water mixture and glycerol was 0.133 and 0.033 .

In the migrating point contact condition (Figure 3(b)) there was no run-in phase for the glycerol and glycerol-water mixture. For glycerol-water mixture, at 11th s of testing the friction coefficient jumped from 0.019 to 0.540 . Similar jump in the friction coefficient for glycerol was recorded at the 32nd s of testing.

In the fixed point-variable speed contact condition (Figure 3(c)) the friction coefficient of the glycerol-water mixture decreased from 0.529 to 0.180 when the sliding speed decreased from $1.30 \mathrm{~m} / \mathrm{s}$ to $0.42 \mathrm{~m} / \mathrm{s}$. The friction coefficient of glycerol was stable at 0.023 when the sliding speed decreased from $1.30 \mathrm{~m} / \mathrm{s}$ to $0.33 \mathrm{~m} / \mathrm{s}$.

3.3. Surface Topography of Wear Tracks and Wear Area. Wear track on the disk after the fixed point contact testing (Figures 4(a) and 4(d)) was smooth. It was only the disk lubricated by the motor oil 5W30 that had a huge pile-up along the sides of the wear track. The worn area on the disk lubricated by the motor oil 5W40 and 5W30 was $1250 \mu \mathrm{m}^{2}$ and $1560 \mu \mathrm{m}^{2}$, respectively. 


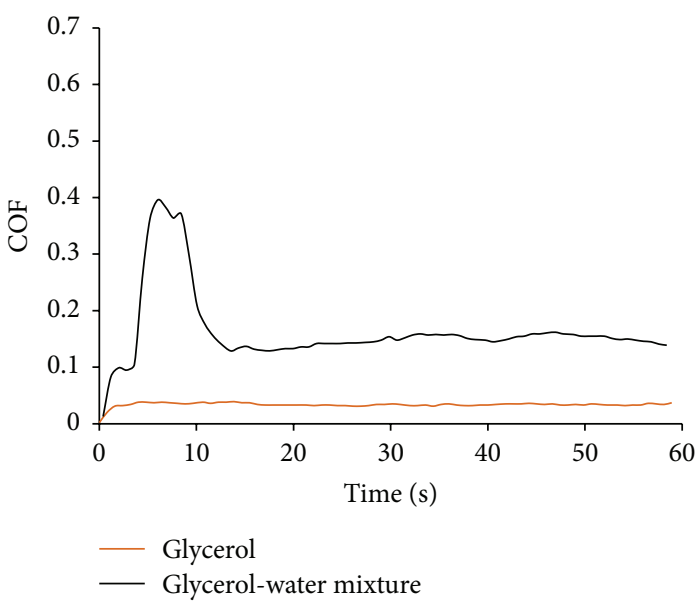

(a)

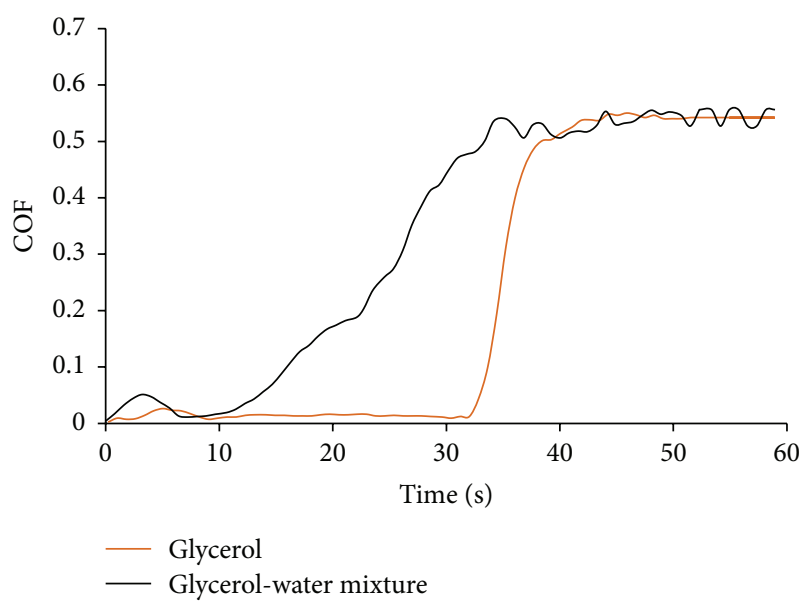

(b)

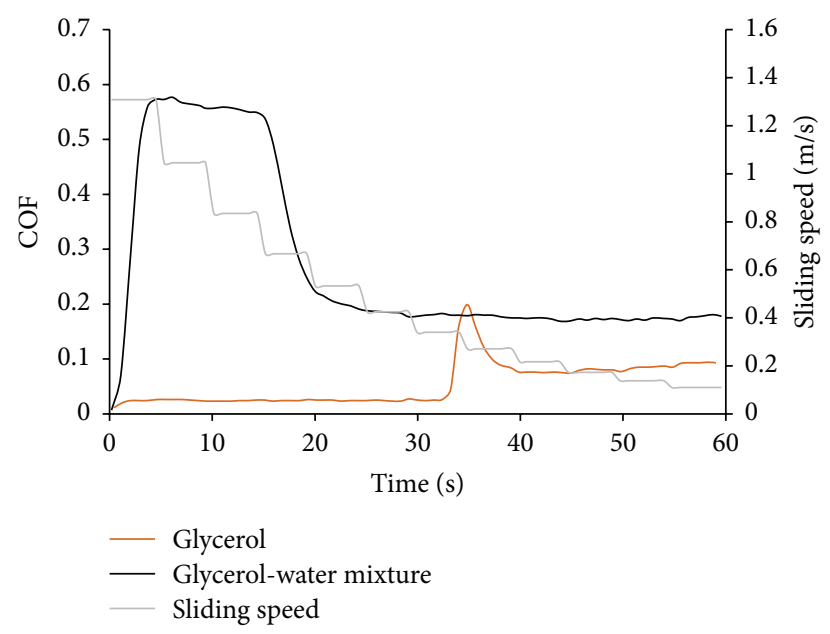

(c)

FIGURE 3: Friction coefficient of glycerol and glycerol-water mixture. (a) fixed point condition and circular geometry, (b) migrating point condition and spiral geometry, and (c) fixed point-variable speed condition and circular geometry.

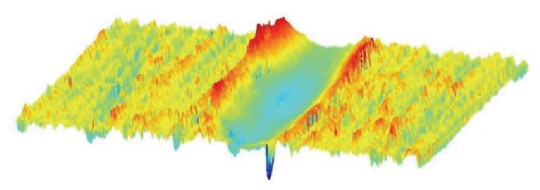

(a) Fixed point; $1564 \mu \mathrm{m}^{2}$ (wear area)

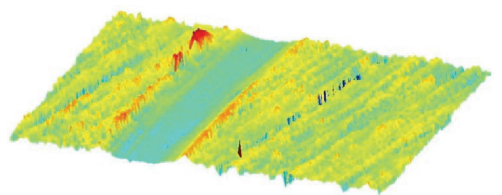

(d) Fixed point; $1250 \mu \mathrm{m}^{2}$ (wear area)

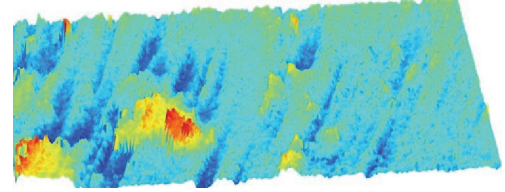

(b) Migrating point; $413 \mu \mathrm{m}^{2}$

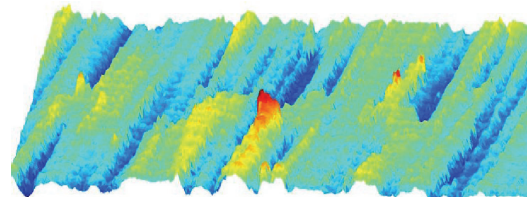

(e) Migrating point; $1866 \mu \mathrm{m}^{2}$

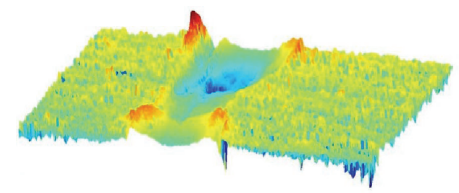

(c) Fixed point-variable speed; $1585 \mu \mathrm{m}^{2}$

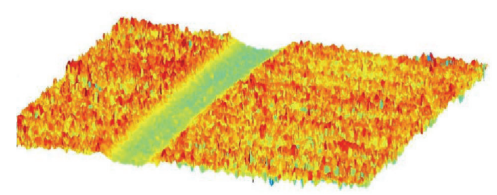

(f) Fixed point-variable speed; $360 \mu \mathrm{m}^{2}$

Figure 4: Surface topography images $(2 \mathrm{~mm} \times 2 \mathrm{~mm})$ of the wear tracks on the disk lubricated by the motor oil 5W30 or 5W40. (a, d) fixed point condition and circular geometry, $(b, e)$ migrating point condition and spiral geometry, and (c, f) fixed point-variable speed condition and circular geometry. 


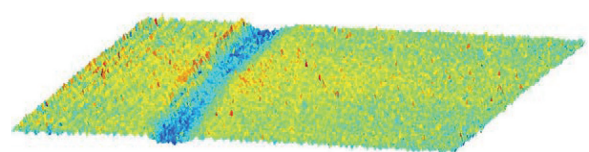

(a) Fixed point; $188 \mu \mathrm{m}^{2}$ (wear area)

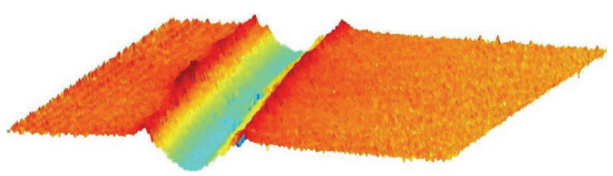

(d) Fixed point; $1664 \mu \mathrm{m}^{2}$ (wear area)

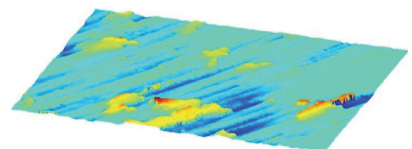

(b) Migrating point; $350 \mu \mathrm{m}^{2}$

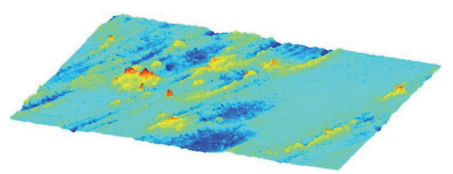

(e) Migrating point; $354 \mu \mathrm{m}^{2}$

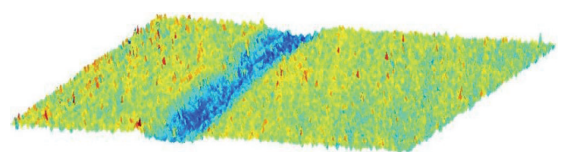

(c) Fixed point-variable speed; $588 \mu \mathrm{m}^{2}$

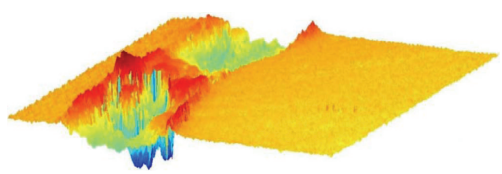

(f) Fixed point-variable speed; $2188 \mu \mathrm{m}^{2}$

FIGURE 5: Surface topography of the wear tracks on the disk lubricated by glycerol or glycerol-water mixture. (a, d) fixed point condition and circular geometry, (b, e) migrating point condition and spiral geometry, and (c, f) fixed point-variable speed condition and circular geometry.

There were several discontinuous scratches on the disk after the migrating point contact testing (Figures 4(b) and $4(\mathrm{e}))$. The area of a scratch on the disk lubricated by the motor oil 5W40 was 4.5 times higher compared to motor oil 5W30.

After the fixed point contact-variable speed testing (Figures $4(\mathrm{c})$ and $4(\mathrm{f})$ ), the disk lubricated by $5 \mathrm{~W} 30$ had wider grooves (Figure $4(\mathrm{c})$ ). The wear on the disk lubricated by $5 \mathrm{~W} 40$ was smooth and its area was 4.4 times lower compared to the motor oil 5W30.

Wear track on the disk lubricated by either glycerol or glycerol-water mixture was smooth after the fixed point contact testing (Figures 5(a) and 5(d)). The worn area due to the glycerol-water mixture was 9 times higher compared to glycerol.

There were several discontinuous, shorter, and deeper scratches after the migrating point contact testing (Figures 5 (b) and 5(e)). The area of a scratch on the disk lubricated either by the glycerol or glycerol-water mixture was the same.

After the fixed point-variable speed contact testing the wear track was smooth when lubricated by glycerol whereas it had deeper grooves when lubricated by glycerol-water mixture (Figures 5(c) and 5(f)). The worn area on the disk lubricated by the glycerol-water mixture was 3.8 times higher compared to the glycerol.

\section{Discussion}

Stability of lubricants is influenced by the wear at the sliding interface. Increase in wear due to plastic deformation will increase the contact area and, theoretically, it decreases the true contact pressure. In such conditions the lubricants tend to show more stability and therefore it is difficult to determine the true stability of a lubricant. Such a situation is expected in the fixed point contact condition where an increase in the friction force is compensated by the decrease in contact pressure. As a result the stable friction profile is observed after the run-in phase. However, the same set of lubricants showed an unstable friction profile when the contact area was fixed (or true contact pressure was fixed) during the test in the migrating point contact condition. The unstable friction profiles include a sudden jump and increase in the friction coefficient. This jump is due to the maximum asperities in contact after the failure of all the lubrication regimes such as hydrodynamic, mixed, and boundary, at the ball and disk interface. Similar profiles are also recorded during the scuffing test where the stability of the lubricants is determined by deliberately increasing the contact pressure until the lubricating films breakdown [6]. In our study, the lubricating films from 5W40 and glycerol failed at a later stage, hence, higher true stability in 5W40 and glycerol compared to 5W30 and glycerol-water mixture. Therefore, we suggest that the true stability of the lubricants can be better evaluated using a migrating point contact condition compared to the fixed point contact condition in the ball-on-disk instrument.

Lubrication efficiency will largely depend on the lubricant viscosity [7], structure, and composition of surface active additives [8]. High viscous lubricants can form a thicker fluid film that separates the contacting bodies; hence, it decreases the friction and the wear in the system [7]. Such a lubrication condition can be related to the low friction and wear behavior of 5W40 and glycerol, in general. However, the mechanism of lubrication after the film failure is complex and it cannot be explained based on the lubricant viscosity. In migrating point contact condition, after the failure of 5W40 lubricant, its friction was higher compared with 5W30. Furthermore, this high friction was translated into more wear despite its higher true stability (Figures 2(b), 4(b), and $4(\mathrm{e})$ ). We hypothesize that the mechanism can be related to the microscopic tribofilms formed after the failure of 5W40 which can be more abrasive compared to 5W30. Note that migrating point contact only minimizes the accumulation of wear debris; however it does not completely block the wear debris accumulating in the contact.

In contrast, the friction profile of glycerol after its failure overlaps with the friction of the glycerol-water mixture. Also, the wear profiles are similar (Figures 3(b), 5(b), and 5(e)). Therefore, we assume that the microscopic tribofilms formed after the failure are similar in nature. However, further investigation on the composition and structure of the tribofilm formed after the failure is necessary to confirm our hypothesis. 
Glycerol can be an alternative to the mineral or synthetic base oil used in the lubricants [9]. In our study, we show that glycerol as a lubricant is more wear resistant and has higher true lubricant stability compared to motor oil 5W40 with synthetic base oil. However the high viscosity in glycerol is an issue, as more energy is needed to shear glycerol, increasing the temperature of the system. To overcome this disadvantage, water is added to the glycerol to decrease its viscosity. Shi et al. [9] showed that the viscosity of glycerolwater mixture $(50 \% \mathrm{w} / \mathrm{w})$ was 100 times lower and the wear after glycerol-water lubrication was 12 times higher than pure glycerol. The same concentration of glycerol-water mixture is used in our study and the results confirm that there is more wear and also high friction. Severity of the wear after glycerolwater lubrication is represented by a huge pile-up on the edges of the wear tack (Figure 5(d)). Spalling that represents the fatigue failure was also observed on the wear tracks of the disk lubricated by the glycerol-water mixture during the fixed point-variable speed contact condition (Figure 5(f)). Therefore, the extent of failure by glycerol-water mixture lubrication is catastrophic compared with pure glycerol lubrication.

\section{Conclusions}

From this tribological investigation of the synthetic and natural lubricants at different point contact conditions, it can be concluded that

(i) true lubricant stability is best studied using the migrating point contact condition in ball-on-disk testing, where there is minimum change in the true contact area and intervention of wear debris;

(ii) low friction coefficient is related to low wear; however there is no relationship between lubricant stability and wear;

(iii) 5W40 has better lubricant stability compared to $5 \mathrm{~W} 30$; however the tribofilm formed after the failure of 5W40 increases the friction and wear;

(iv) glycerol shows the lowest friction and its film stability is better than the synthetic oils like 5W40 and 5W30;

(v) addition of water to the glycerol increases the friction and wear; also, it reduces the true film stability of pure glycerol.

\section{Conflict of Interests}

The authors declare that there is no conflict of interests regarding the publication of this paper.

\section{References}

[1] ASTM, "Standard test method for measurement of extremepressure properties of lubricating fluids (Four-Ball method)," ASTM D2783-03, 2009.

[2] ASTM, "Standard test method for wear testing with a pinon-disk apparatus," ASTM G99-05, ASTM International, West Conshohocken, Pa, USA, 2010.
[3] ASTM, "Standard test method for measurement of extremepressure properties of lubricating fluids (Timken method)," ASTM D2782-02, ASTM International, West Conshohocken, $\mathrm{Pa}, \mathrm{USA}, 2014$.

[4] O. Bridgeman, "The present status of the extreme pressure lubrication problem," SAE Technical Paper 340011, 1934.

[5] J. Enthoven and H. A. Spikes, "Infrared and visual study of the mechanisms of scuffing," Tribology Transactions, vol. 39, no. 2, pp. 441-447, 1996.

[6] ASTM, "Standard test method for evaluating the scuffing load capacity of oils," ASTM D5182-97, ASTM International, West Conshohocken, Pa, USA, 2014.

[7] M. Castro and J. Seabra, "Scuffing and lubricant film breakdown in FZG gears part II. New PV scuffing criteria, lubricant and temperature dependent," Wear, vol. 215, no. 1-2, pp. 114-122, 1998.

[8] H. Y. Chu, W. C. Hsu, and J. F. Lin, "The anti-scuffing performance of diamond nano-particles as an oil additive," Wear, vol. 268, no. 7-8, pp. 960-967, 2010.

[9] Y. Shi, I. Minami, M. Grahn, M. Björling, and R. Larsson, "Boundary and elastohydrodynamic lubrication studies of glycerol aqueous solutions as green lubricants," Tribology International, vol. 69, pp. 39-45, 2014. 


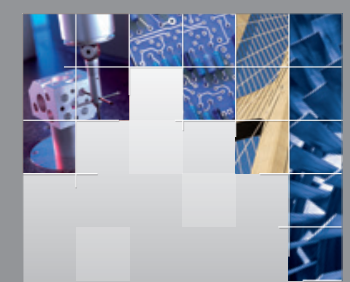

\section{Enfincering}
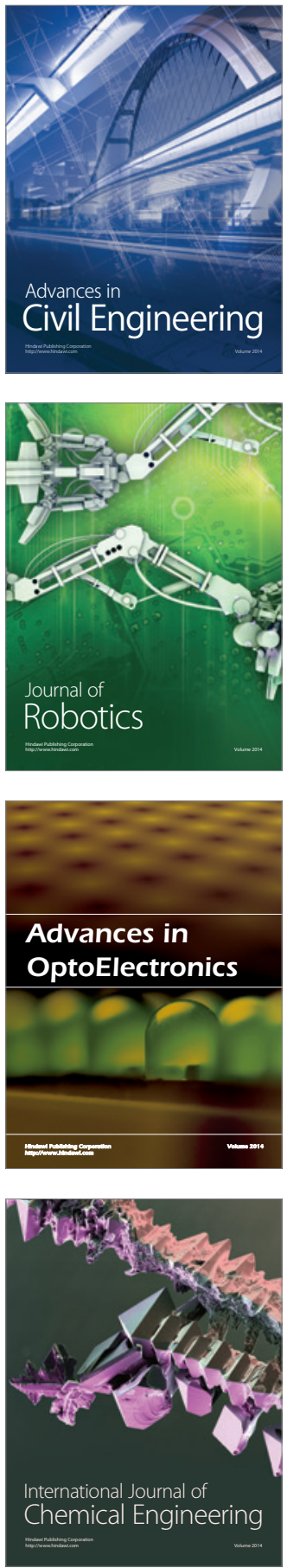

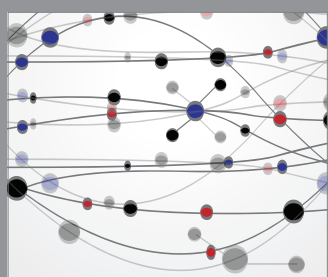

The Scientific World Journal

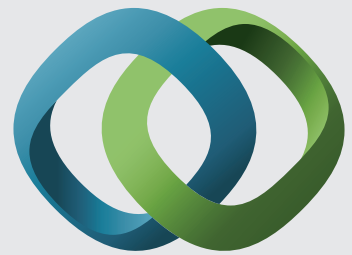

\section{Hindawi}

Submit your manuscripts at

http://www.hindawi.com
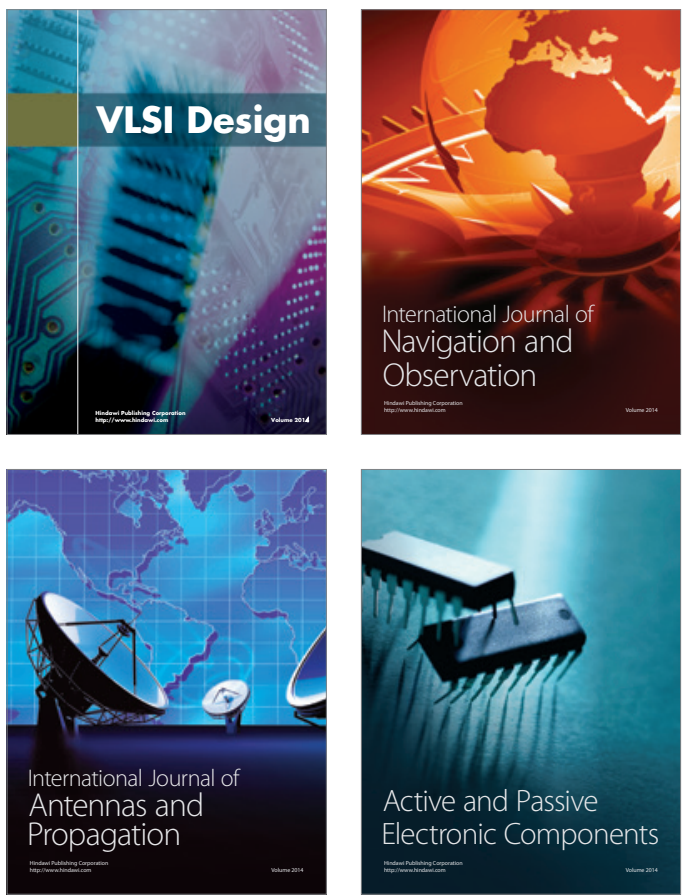
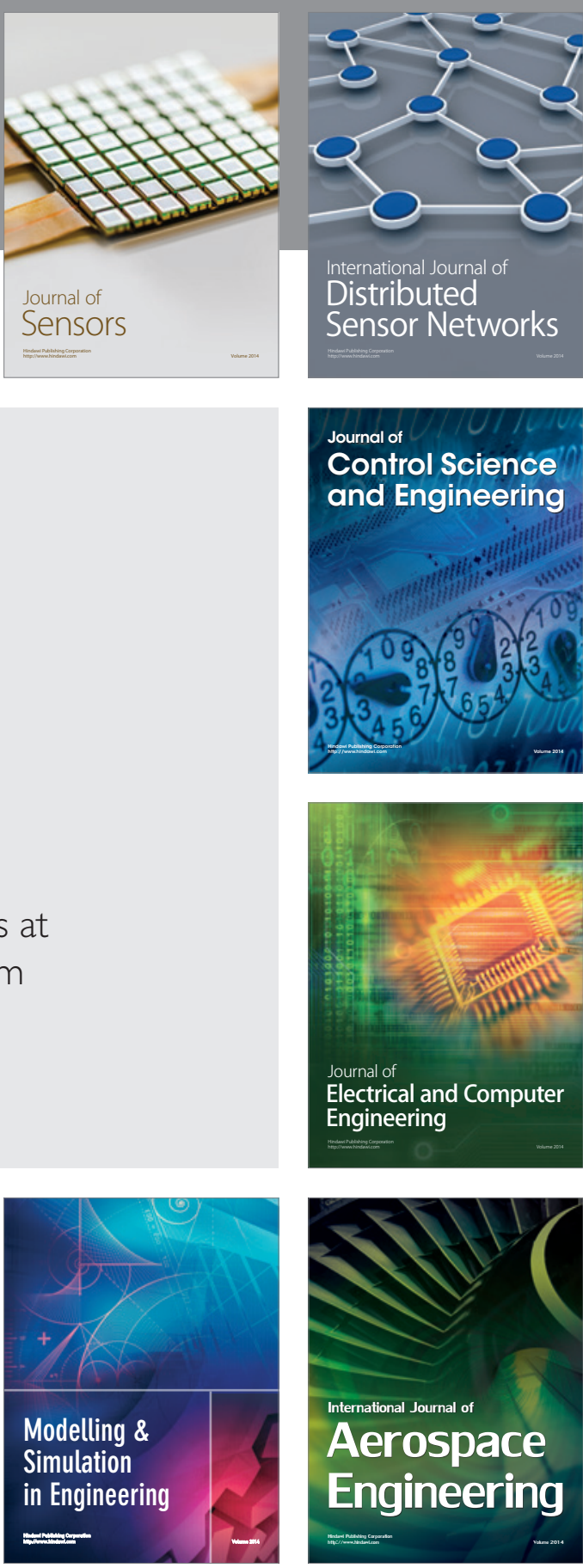

International Journal of

Distributed

Sensor Networks

Journal of

Control Science

and Engineering
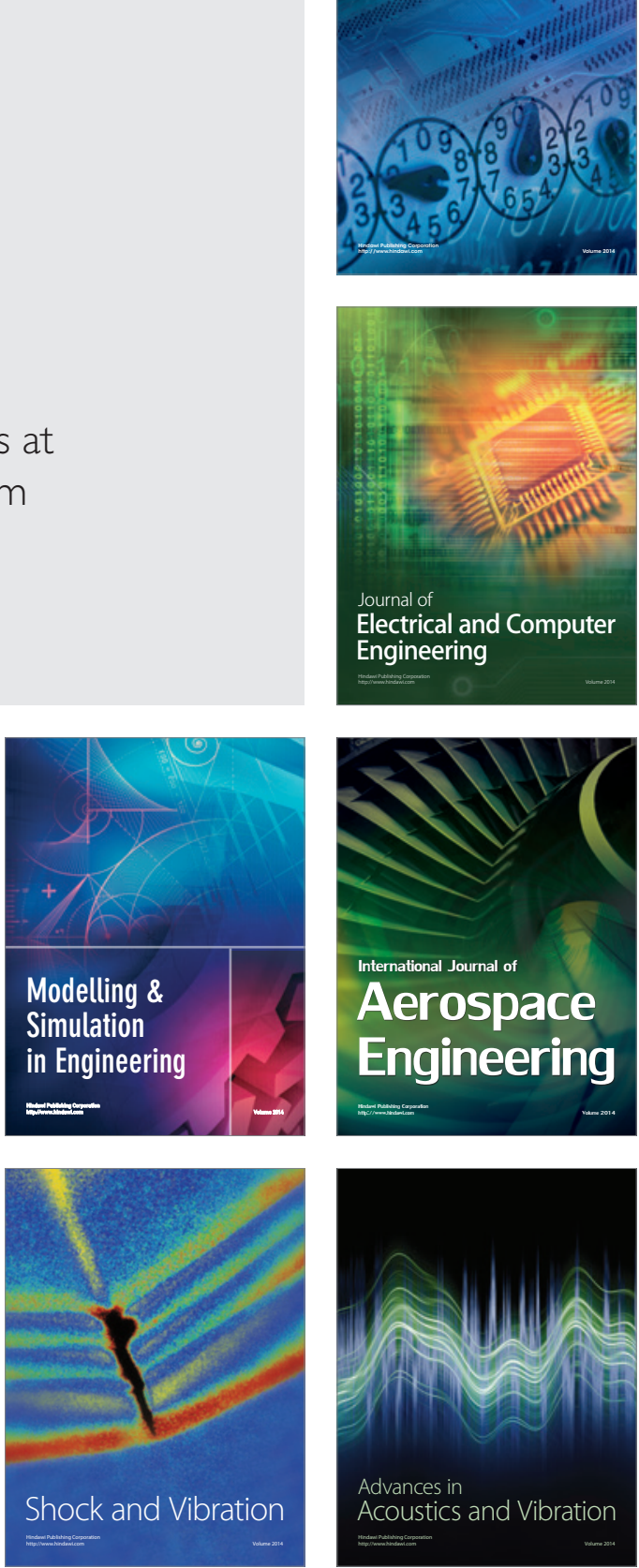